\title{
The Impact of Spinal Anesthesia and Use of Oxytocin on Fluid Absorption in Patients Undergoing Operative Hysteroscopy: Results from a Prospective Controlled Study
}

This article was published in the following Dove Press journal:

International Journal of Women's Health

\author{
Naser Al-Husban (D) \\ Abdelkarim Aloweidi ${ }^{2}$ \\ Omar Ababneh ${ }^{2}$ \\ 'Obstetrics and Gynecology \\ Department, School of Medicine, The \\ University of Jordan, Amman, Jordan; \\ ${ }^{2}$ Department of Anesthesia, School of \\ Medicine, The University of Jordan, \\ Amman, Jordan
}

\begin{abstract}
Objective: The aim of this study was to determine if combining intravenous oxytocin infusion and spinal anesthesia will reduce the amount of glycine absorption in patients undergoing operative hysteroscopy.

Patients and Methods: A prospective controlled study was conducted in premenopausal patients who had hysteroscopic surgery including endometrial resection, endometrial polypectomy, myomectomy resection and uterine septal resection. The effect of combined spinal anesthetic with oxytocin infusion on fluid deficit was studied.

Results: A total of 88 patients were studied. Sixty-two cases were done under general anesthesia (control group) and 26 cases were performed with spinal anesthesia and the use of oxytocin infusion (study group). There was a statistically significant less mean fluid deficit in the study group than control group in the endometrial polypectomy patients $(220 \pm 36 \mathrm{~mL}$ vs $392 \pm 178 \mathrm{~mL}$, respectively, P value $0.010,95 \%$ C.I.: $163-276)$ and the myomectomy patients $(308 \pm 66 \mathrm{~mL}$ vs $564 \pm 371 \mathrm{~mL}$, respectively, $\mathrm{P}$ value $0.003,95 \%$ C.I.: $239-378)$. In the endometrial resections, there was also a statistically significant less mean fluid deficit in the study than the control group ( $\mathrm{P}$ value $<0.001$ ). Regarding septal resection, there was no statistically significant difference in the mean fluid deficit between the two groups ( $\mathrm{P}$ value 0.833).

Conclusion: Spinal anesthesia combined with intravenous oxytocin infusion in operative hysteroscopy results in a statistically significant reduction in the glycine fluid deficit than the general anesthesia. We also recommend studying the effects of this combination in operative hysteroscopy using bipolar devices with isotonic solutions.
\end{abstract}

Keywords: anesthesia, deficit, glycine, hysteroscopy, spinal, resection, myomectomy, polypectomy

\section{Introduction}

Operative hysteroscopy using glycine as a distending medium has the potential for serious complications like uterine perforation, haemorrhage, gas or air embolism, sepsis and fluid overload with hyponatraemia and brain edema. ${ }^{1,2}$ Excessive glycine overload may cause a toxicity syndrome called Operative Hysteroscopy Intravascular Absorption (OHIA) syndrome. ${ }^{3}$

This syndrome is similar to Transurethral Resection of Prostate (TURP) syndrome therefore, it was given the alternate term gynaecological TURP syndrome. ${ }^{4}$
Correspondence: Naser Al-Husban Obstetrics and Gynecology Department, School of Medicine, The University of Jordan, P O Box 2194, Amman II94I, Jordan

Tel +962772086080

Fax+96264643217

Email Husban48@yahoo.com 
It usually has an abrupt presentation intra-operatively., General anesthesia (GA) during such surgical procedures precludes the use of patient's mental status as an indicator of glycine intoxication and dilutional hyponatremia. ${ }^{6}$

Due to the serious complications of glycine overload, the optimal goal should be to prevent glycine overload and its serious complications.

Our objective was to find out if combining intravenous oxytocin infusion with spinal anesthesia will reduce the amount of glycine absorption in patients undergoing operative hysteroscopy. Our aim was not to investigate the individual effect of oxytocin or spinal anesthesia.

Our hypothesis was that the combination of spinal anesthesia and oxytocin infusion can reduce the amount of glycine absorbed by the patient, hence reducing the fluid deficit.

\section{Patients and Methods}

\section{Trial Design: Prospective Comparative \\ Trial}

Participants

Patients undergoing operative hysteroscopy including hysteroscopic endometrial resection, endometrial polypectomy, myomectomy or septoplasty (septal resection with no excision).

\section{General Information}

The patients were premenopausal with no cardiovascular comorbidities. The procedures were performed at a university hospital in the period 2018-2019. All patients underwent general and gynecologic examination before surgery. All patients had either trans-vaginal ultra-sound (U/S) scan done by consultant gynecologists to accurately measure the uterine size, endometrial thickness and the size of the fibroids or polyps, or diagnostic hysteroscopy or both before surgery. For each type of surgery, we included patients with comparable features including uterine size and endometrial thickness. Patients with fibroids or polyps had comparable size of their lesions. We excluded endometrial cancer cases, patients who received pre-operative hormonal preparations, previously resected cases and cases done using bipolar diathermy.

\section{Informed Consent}

A written informed consent has been obtained from all individuals included in this study. The consent included full explanation of the procedure, complications, risks and potential benefits.

\section{Surgical Technique}

The procedures were performed in the early follicular phase of the menstrual period. The operative hysteroscopy at our hospital was mostly performed using rigid, with 30 degrees angulated continuous flow hysteroscopy with monopolar resectoscope (with selected cases being performed using bipolar resectoscope) which necessitated the use of glycine $1.5 \%$ as a uterine distending medium. This practice was due to financial issues since the monopolar resectoscope was sterilizable and reusable while the bipolar one was a single-use instrument. The flow rate was at $250 \mathrm{~mL} /$ minute. The endometrial resection and myomectomy cases were performed using angled wire cutting loop electrodes. The septal resection was performed using angulated wire needle electrode. For fluid distension, we used bags of 3.0- Liter-glycine 1.5\%. All patients had standardized 80 millimeter mercury $(\mathrm{mmHg})$ of intrauterine pressure during surgery with the use of the same automated glycine infusion pump.

We used a high-frequency electrosurgical generator unit. Tissues were removed manually using ovum forceps. All samples were subjected to histopathological examination.

Our intervention was the combination of spinal anesthesia and oxytocin use in these operative hysteroscopic procedures. We had two groups; the first group (control group) included those who underwent resection under general anesthesia and with no use of oxytocin while the second group (study group) was operated upon under spinal anesthetic and with oxytocin infusion of 10 international units (IU) in $200 \mathrm{~mL}$ normal saline started immediately after the spinal injection and maintained until the end of the operation.

\section{Anesthesia Technique}

Patients were anesthetized using similar standardized general or spinal anesthetic as per hospital practice. We found a substantial difficulty in recruiting patients for spinal anesthesia as they mostly preferred to sleep during surgery and not to be awake. All patients were assessed preoperatively and were American society of anesthesia classification (ASA) 2 or 3. They were all fasting. No pre-medications were given. Anesthesia types were established after approval and with written consents of each patient. The general anesthesia patients had standardized monitoring and induction with Fentanyl and Propofol then laryngeal mask (for low-risk patients) with Isoflurane maintenance and controlled mechanical ventilation or Fentanyl, Propofol and 
Cisatracurium as muscle relaxant with endotracheal tube (for patients with anesthetic considerations including obesity and those with gastric reflux) as indicated and Isoflurane maintenance with controlled mechanical ventilation. The patients who received muscle relaxant were reversed by Neostigmine and Atropine at the end of surgery. All were extubated easily after surgery. The study group were with spinal neuraxial block at the level of lumbar spines L3-L4, L4-L5 were given heavy plain Bupivacaine 10.0 milligrams $(\mathrm{mg}) ;(5.0 \mathrm{mg} / \mathrm{mL}$, $0.5 \%$ of $2 \mathrm{~mL}$ ) with Fentanyl $25 \mu \mathrm{gm}$ intrathecally under aseptic technique. All patients were maintained on intravenous fluids $120 \mathrm{~mL} /$ hour and any fluid deficit was replaced. All patients in both groups received prophylactic antibiotics at induction of anesthesia in the form of 2 grams of cefazolin intravenously. All operative procedures were performed by one gynecologic endoscopist. The general and spinal anesthesia were performed by different consultants and senior resident anesthesiologists. Because a spectrum of procedures exists and each of which has a different risk for systemic absorption, each type of surgery was compared independently between the study and control groups. The assignment to groups was done to show the effect of oxytocin and spinal anesthesia on fluid absorption in different surgical scenarios.

\section{Measurements Collected and Primary Outcome}

We recorded the patients' body mass index (BMI), the mean intraoperative blood pressure (BP) and the duration of the operation (from the beginning of cervical dilation to the end of the procedure). The mean intraoperative BP was calculated as the average of three values at the beginning of surgery, 10 minutes after starting surgery and at the end of the surgical procedure. To measure the fluid deficit, the suction tube was connected to a suction container and any fluid expelled outside the suction system was collected in a plastic bag underneath the patient's buttocks. This method was already in use in all operative hysteroscopic procedures at JUH. The deficit was calculated by subtracting the total fluid volume in the container bottle and the plastic bag from the whole volume used.

The primary outcome was the amount of fluid (glycine) absorption (fluid deficit).

\section{Statistical Methods}

We used IBM SPSS statistics software version 1.0.0-3112. We calculated independent sample $t$-test (for $p$ value significant at $<0.05)$ and descriptive statistics with $95 \%$ confidence intervals. As a prospective study, we selected all the patients in the study period who fulfilled the criteria and they underwent the hysteroscopic operative procedures under either general anesthesia or spinal anesthesia with oxytocin infusion. The study was powered for the primary outcome (the power was 0.8 ).

\section{Ethical Approval}

The research related to human use has been compiled with all the relevant national regulations, institutional policies, and in accordance with the tenets of the Helsinki declaration and has been approved by the authors institutional review board. The study obtained the approval of the institutional review board (IRB) at the Jordan University Hospital with decision number 2018/172 dated 2018/5/10. Our study conformed to the Enhancing the QUAlity and Transparency Of health Research (EQUATOR) network guidelines.

\section{Results}

There were 88 operative hysteroscopic procedures performed. Sixty-two cases $(70.5 \%)$ were done under general anesthesia (control group) and 26 cases (29.5\%) were performed with spinal anesthesia and the use of oxytocin infusion (study group). The acceptance of spinal anesthesia in our patients was very low even after adequate counselling and explanation. Among patients in the control group, there were 14 endometrial polypectomies, 26 myomectomies, 11 trans-cervical resection of the endometrium (TCRE) and 11 septal resections. In the study group, there were 4 endometrial polypectomies, 6 myomectomies, 14 TCRE and 2 septal resections. The surgical procedures were divided into four groups because they were different. Each group included similar surgeries. This division was performed so that we could compare similar surgical procedures between the control and the study groups.

Concerning the endometrial polypectomy cases, the mean body mass index (BMI) was not different between the cases in the control and study groups (29.6 vs 33, respectively, $\mathrm{P}$ value 0.654 ). The mean uterine size in weeks and mean endometrial thickness in millimeters (mm) were significantly less in the control than the study group (7.4 \pm 1.2 weeks vs $9.7 \pm 1.5$ weeks, and $10.3 \pm 2.2 \mathrm{~mm}$ vs $13.8 \pm 2.6 \mathrm{~mm}$, respectively). The mean BMI, uterine size and ET in the myomectomy were comparable between the two groups. Regarding the TCRE, the mean ET was significantly more in the study than the control group (14 $\pm 3.3 \mathrm{~mm}$ vs $10.2 \pm 3.3 \mathrm{~mm}$, respectively, $P$ value 0.009 with 
Table I Mean BMI, Uterine Size, and Endometrial Thickness (ET)

\begin{tabular}{|c|c|c|c|c|c|c|}
\hline & \multicolumn{3}{|c|}{ General Anesthesia } & \multicolumn{3}{|c|}{ Spinal Anesthesia } \\
\hline & Mean \pm S.D. & S.E. & C.I. & Mean \pm S.D. & S.E. & C.I. \\
\hline Resection of endometrial polyp & \multicolumn{3}{|l|}{ (II) } & \multicolumn{3}{|l|}{ (4) } \\
\hline Mean BMI & $29.6 \pm 4.0$ & I.I & $27.3-31.9$ & $33.0 \pm 13.5$ & 6.7 & II.6-54.4 \\
\hline Mean uterine size (weeks) & $7.4 \pm 1.2$ & 0.3 & $6.7-8.0$ & $9.7 \pm 1.5$ & 0.9 & $5.9-13.5$ \\
\hline Mean ET (mm) & $10.3 \pm 2.2$ & 0.6 & $9.0-11.6$ & $13.8 \pm 2.6$ & 1.3 & $9.6-17.9$ \\
\hline Hysteroscopic myomectomy & \multicolumn{3}{|l|}{ (26) } & \multicolumn{3}{|l|}{ (6) } \\
\hline Mean BMI & $29.4 \pm 4.6$ & 0.9 & $27.5-31.2$ & $29.8 \pm 5.2$ & 2.1 & $24.3-35.3$ \\
\hline Mean uterine size (weeks) & $9.5 \pm 2.1$ & 0.4 & $8.7-10.4$ & $9.7 \pm 1.5$ & 0.6 & $8.1-11.2$ \\
\hline Mean ET $(\mathbf{m m})$ & $10.5 \pm 3.0$ & 0.6 & $9.2-11.7$ & $11.7 \pm 0.8$ & 0.3 & $10.8-12.5$ \\
\hline TCRE & \multicolumn{3}{|l|}{ (II) } & \multicolumn{3}{|l|}{$(14)$} \\
\hline Mean BMI & $29.8 \pm 5.8$ & 1.7 & $25.9-33.7$ & $27.2 \pm 6.7$ & 1.8 & $23.3-31.0$ \\
\hline Mean uterine size (weeks) & $9.4 \pm 1.7$ & 0.5 & $8.3-10.5$ & $10.4 \pm 1.7$ & 0.5 & $9.4-11.4$ \\
\hline Mean ET $(\mathbf{m m})$ & $10.2 \pm 3.3$ & 1 & $8.0-12.4$ & $14.0 \pm 3.3$ & 0.9 & $12.1-15.9$ \\
\hline Resection of septum & \multicolumn{3}{|l|}{ (II) } & \multicolumn{3}{|l|}{$(2)$} \\
\hline Mean BMI & $29.1 \pm 3.6$ & 1.1 & $26.6-31.5$ & $20.5 \pm 0.7$ & 0.5 & $14.1-26.9$ \\
\hline Mean uterine size (weeks) & $6.5 \pm 0.7$ & 0.2 & $6.0-6.9$ & $8.5 \pm 2.1$ & 1.5 & $10.6-27.6$ \\
\hline Mean ET $(\mathbf{m m})$ & $9.3 \pm 1.8$ & 0.5 & $8.1-10.5$ & $12.0 \pm 2.8$ & 2 & 13.4-37.4 \\
\hline
\end{tabular}

Notes: S.D. $=$ standard deviation, S.E. $=$ standard error, C.I. = confidence interval.

Abbreviations: BMI, body mass index; ET, endometrial thickness.

Table 2 Mean Arterial Blood Pressure (MAP), Duration of Surgery, Estimated Blood Loss (EBL), and Size of Polyp/Fibroid Lesions

\begin{tabular}{|c|c|c|c|c|c|c|c|}
\hline & \multicolumn{3}{|c|}{ General Anesthesia } & \multicolumn{3}{|c|}{ Spinal Anesthesia } & \multirow[t]{2}{*}{ p-value } \\
\hline & Mean \pm S.D. & S.E. & C.I. & Mean \pm S.D. & S.E. & C.I. & \\
\hline Resection of endometrial polyp & \multicolumn{3}{|l|}{ (II) } & \multicolumn{3}{|l|}{ (4) } & \\
\hline MAP & $81.0 \pm 15.0$ & 4.0 & $72.3-89.7$ & $88.3 \pm 6.1$ & 3.0 & $78.6-97.9$ & 0.174 \\
\hline Duration of surgery (min) & $36.4 \pm 20.5$ & 5.5 & $24.6-48.3$ & $37.5 \pm 8.7$ & 4.3 & $23.7-51.3$ & 0.880 \\
\hline EBL (cc) & $59.3 \pm 33.8$ & 33.8 & $39.7-78.8$ & $60.0 \pm 46.2$ & 23.1 & $13.5-133.5$ & 0.973 \\
\hline Size of polyp $(\mathrm{cm})$ & $2.7 \pm 0.9$ & 0.2 & $2.1-3.2$ & $3 \pm 0.8$ & 0.4 & $1.7-4.3$ & 0.543 \\
\hline Hysteroscopic myomectomy & \multicolumn{3}{|l|}{ (26) } & \multicolumn{3}{|l|}{ (6) } & \\
\hline MAP & $82.3 \pm 10.8$ & 2.1 & $77.9-86.7$ & $83 \pm 5.7$ & 2.3 & $77.0-90.0$ & 0.829 \\
\hline Duration of surgery (min) & $43.8 \pm 22.9$ & 4.5 & $34.6-53.1$ & $39.2 \pm 12.0$ & 4.9 & $26.6-51.7$ & 0.492 \\
\hline EBL (cc) & $83.8 \pm 57.9$ & 11.4 & $60.5-107.2$ & $61.7 \pm 69.1$ & 28.2 & $10.9-134.2$ & 0.490 \\
\hline Size of fibroid $(\mathrm{cm})$ & $4.4 \pm 1.9$ & 0.4 & $3.6-5.2$ & $3.2 \pm 1.5$ & 0.6 & $1.6-4.7$ & 0.110 \\
\hline TCRE & \multicolumn{3}{|l|}{ (II) } & \multicolumn{3}{|l|}{ (14) } & \\
\hline MAP & $87.0 \pm 10.0$ & 3.0 & $80.3-93.7$ & $87.8 \pm 12.7$ & 3.4 & $80.5-95.1$ & 0.868 \\
\hline Duration of surgery (min) & $34.5 \pm 11.3$ & 3.4 & $27.0-42.1$ & $51.1 \pm 12.9$ & 3.4 & $43.6-58.5$ & 0.003 \\
\hline EBL (cc) & $47.3 \pm 9.0$ & 2.7 & $41.2-53.3$ & $64.3 \pm 50.8$ & 13.6 & $35.0-93.6$ & 0.239 \\
\hline Resection of septum & \multicolumn{3}{|l|}{ (II) } & \multicolumn{3}{|l|}{$(2)$} & \\
\hline MAP & $82.5 \pm 8.0$ & 2.4 & $77.2-87.9$ & $75.0 \pm 2.8$ & 2.0 & $49.6-100.4$ & 0.061 \\
\hline Duration of surgery (min) & $49.5 \pm 23.3$ & 7.0 & $33.9-65.2$ & $40.0 \pm 0$ & 0 & $40-40$ & 0.204 \\
\hline EBL (cc) & $71.8 \pm 51.5$ & 15.5 & $37.2-106.4$ & $65.0 \pm 49.5$ & 35.0 & $379.7-509.7$ & 0.866 \\
\hline
\end{tabular}

Notes: S.D. = standard deviation, S.E. = standard error, C.I. = confidence interval. The size of fibroids was measured by consultant gynecologist using a high-resolution transvaginal ultrasound.

Abbreviations: MAP, mean arterial blood pressure; EBL, estimated blood loss; TCRE, trans-cervical resection of the endometrium. 
Table 3 Number of Surgeries and Mean Fluid Deficit per Type of Surgery

\begin{tabular}{|c|c|c|c|c|c|c|c|}
\hline & \multicolumn{3}{|c|}{ General Anesthesia } & \multicolumn{3}{|c|}{ Spinal Anesthesia } & \multirow[t]{2}{*}{ p-value } \\
\hline & Mean \pm S.D. & S.E. & C.I. & Mean \pm S.D. & S.E. & C.I. & \\
\hline \multicolumn{8}{|c|}{ Resection of Endometrial Polyp } \\
\hline Number of cases & \multicolumn{3}{|l|}{14} & \multicolumn{3}{|l|}{4} & \\
\hline Mean fluid deficit (cc) & $392 \pm 178$ & 54 & $272-511$ & $220 \pm 36$ & 18 & $163-276$ & 0.010 \\
\hline \multicolumn{8}{|c|}{ Hysteroscopic Myomectomy } \\
\hline Number of cases & \multicolumn{3}{|l|}{26} & \multicolumn{3}{|l|}{6} & \\
\hline Mean fluid deficit (cc) & $564 \pm 371$ & 74 & $4|I-7| 7$ & $308 \pm 66$ & 27 & $239-378$ & 0.003 \\
\hline \multicolumn{8}{|l|}{ TCRE } \\
\hline Number of cases & \multicolumn{3}{|l|}{11} & \multicolumn{3}{|l|}{14} & \\
\hline Mean fluid deficit (cc) & $790 \pm 318$ & 100 & $563-1017$ & $229 \pm 75$ & 20 & $185-272$ & $<0.001$ \\
\hline \multicolumn{8}{|l|}{ Resection of Septum } \\
\hline Number of cases & \multicolumn{3}{|l|}{11} & \multicolumn{3}{|l|}{2} & \\
\hline Mean fluid deficit (cc) & $781 \pm 429$ & 129 & $494-1070$ & $1000 \pm 1131$ & 800 & $9165-11,165$ & 0.833 \\
\hline
\end{tabular}

Notes: S.D. = standard deviation, S.E. = standard error, C.I. = confidence interval. Abbreviation: TCRE, trans-cervical resection of the endometrium.

95\% C.I.: 12.1-15.9), while the mean BMI and uterine size were not significantly different (Table 1).

In the patients who underwent septal resection, the mean uterine size and ET were not significantly different between the control and the study patients. The mean BMI was significantly more in the control than the study group (29.1 vs 20.5, respectively, P value <0.001) (Table 1).

In the patients who underwent septal resection, endometrial polypectomies and myomectomies, there were no statistically significant differences between the two groups regarding the intraoperative mean arterial blood pressure (MAP), duration of surgery (in minutes), estimated blood loss (EBL) (in milliliters) and mean size of the polyps or the fibroids.

Regarding the TCRE, the mean duration of surgery was significantly longer in the spinal than the general anesthesia $(51.1 \pm 12.9$ minutes vs $34.5 \pm 11.3$ minutes, respectively, $\mathrm{P}$ value 0.003 , 95\% C.I.: 43.6-58.5). The MAP and EBL were not statistically different between the general and spinal anesthesia (Table 2).

Statistically, the mean fluid deficit in the spinal anesthesia with oxytocin infusion (the study group) was significantly less than in the general anesthesia (control group) in the endometrial polypectomy patients (220 $\pm 36 \mathrm{~mL}$ vs $392 \pm 178 \mathrm{~mL}$, respectively, $\mathrm{P}$ value 0.010 ,
95\% C.I.: 163-276) and the myomectomy patients (308 $\pm 66 \mathrm{~mL}$ vs $564 \pm 371 \mathrm{~mL}$, respectively, P value $0.003,95 \%$ C.I.: 239-378) (Table 3).

In the TCRE, there was also a statistically significant less mean fluid deficit in the study than the control group $(229 \pm 75 \mathrm{~mL}$ vs $790 \pm 318 \mathrm{~mL}$, respectively, $\mathrm{p}$ value $<0.001$, 95\% C.I.: 185-272) (Table 3).

Regarding septal resection, there was no statistically significant difference in the mean fluid deficit between the two groups, $\mathrm{P}$ value 0.833 (Table 3 ).

There was one case of uterine perforation after septal resection in the general anesthetic group. Diagnostic laparoscopy showed a very small $0.5 \mathrm{~cm}$ hole in the anterior uterine wall. The perforation was managed conservatively and the patient was discharged on oral antibiotics. Hysterosalpingography (HSG) subsequently showed a normal uterine cavity.

There were no other complications in our patients indicating safety issues of this combination.

\section{Discussion}

Our patients were assessed pre-operatively by either transvaginal U/S scan or diagnostic hysteroscopy or both. Diagnostic hysteroscopy was used when the transvaginal $\mathrm{U} / \mathrm{S}$ scan result was inconclusive. The combination of 
transvaginal U/S and hysteroscopy was recommended to plan an appropriate management of intrauterine disease. ${ }^{7,8}$ According to an overview by Di Spiezio Sardo et al, none of the available methods for endometrial evaluation was ideal and each one has pros and cons. ${ }^{9}$

In our hospital, almost all our cases of operative hysteroscopy were performed using monopolar resectoscope and glycine distension medium. The upper fluid deficit levels for hypotonic solutions were suggested to be $750 \mathrm{~mL} .{ }^{10}$ We used a similar intrauterine pressure of $80 \mathrm{mmHg}$ which was lower than the MAP in both the control and the general group. This pressure contributed to the generally low fluid deficit in our patients. Systemic absorption of fluid increases considerably when intrauterine pressure exceeds mean arterial pressure. ${ }^{11}$ This may explain the relatively high mean fluid deficit (1000 $\mathrm{mL})$ in the study group with the two septal resections. In these two cases the mean intrauterine pressure (80 $\mathrm{mmHg}$ ) was higher than the intraoperative MAP (75 mm Hg) and there was not a statistically significant difference in the fluid deficit between the control and study groups. Also they were only two cases in the study group which could have contributed to this statistical finding.

Regarding the TCRE, the depth of myometrial penetration was the same between the control and the study group. All procedures were done by the same gynecologist. The mean duration of surgery was not statistically different between the two groups in the polypectomy, myomectomy and septal resection patients. In fact, in the TCRE, it was longer in the study than the control group. The longer duration of surgery in the study than the control group (mean $\pm \mathrm{SD})(51.1 \pm 12.9$ minutes vs $34.5 \pm 11.3$ minutes, $\mathrm{P}$ value 0.003 ) was expected to be associated with more fluid absorption. On the contrast, the fluid deficit was significantly less in the study than the control group (the mean fluid deficit was $229 \pm 75 \mathrm{~mL}$ vs 790 $\pm 318 \mathrm{~mL}, \mathrm{P}$ value $<0.001)$. This difference added a credit to the effect of the oxytocin and the spinal anesthetic and indicated that the combined use of spinal anesthesia and oxytocin use was the remaining explanation for the lower fluid deficit in the study group. The longer the procedure, the more fluid accumulation within the body was to be expected. ${ }^{12}$ We measured the duration of surgery from the beginning of the operative procedure. The larger the uterine cavity, the greater the endometrial surface for fluid absorption. ${ }^{13}$ On the contrast, despite that in our polypectomy patients the mean uterine size was significantly larger in the study than the control group; the fluid absorption was less in the former. Despite that in the TCRE patients, the mean ET was significantly larger in the study group; the fluid deficit was significantly less in the study than the control group. The larger mean uterine size and ET with less fluid deficit in the study than the control group added further credit to the beneficial effects of oxytocin and spinal anesthetic in decreasing fluid absorption. With large uterine size and ET, we would expect more fluid absorption. So the only explanation for the less fluid absorption was the combined spinal anesthesia and oxytocin use.

We did not use gonadotrophin releasing hormone $(\mathrm{GnRH})$ agonists in any of our patients. The data about this issue were controversial. Mavrelos et $\mathrm{al}^{14}$ did not show a statistically significant difference in fluid deficit with the use of pre-operative GnRH agonists. Muzii et al ${ }^{15}$ found that GnRH agonist seemed to reduce the absorption of the fluid in a prospective-randomized multicentre trial of hysteroscopic resection of submucous myomas. Laganà et $\mathrm{al}^{16}$ in a prospective, randomized, parallel-group study to compare desogestrel and danazol as preoperative endometrial preparation agents for hysteroscopic surgery, found that desogestrel showed most marked effect in inducing endometrial atrophy, allowed a better intraoperative management and caused less side effects during treatment. Kodama et al $^{17}$ concluded that administration of dienogest may be an effective and convenient treatment before hysteroscopy. Laganà et al, ${ }^{18}$ found in a systematic review that, despite Dienogest may be an effective and safe treatment for endometrial thinning before operative hysteroscopy, this conclusion was based on few reports and further studies to prove or disprove it are warranted. In an office setting, Cicinelli et $\mathrm{al}^{19}$ found that at 10 days before surgery, administration of Qlaira was effective for preparation of the endometrium for hysteroscopic polypectomy. In their study, the surgical procedure could be performed more easily and faster, and both surgeon and patient satisfaction rates were improved.

All our patients were operated upon in the early follicular phase of the cycle when the endometrium was very thin.

After adjusting for other confounding variables, oxytocin infusion in our study should have, at least partially, played a role in the significantly lower fluid deficit in the study group in the polypectomy, myomectomy and TCRE. Oxytocin receptors exist in the non-pregnant uterus at lower concentration than in pregnancy. It is for this reason 
that the clinical use of oxytocin outside of pregnancy is limited. ${ }^{20,21}$ Shokeir et $\mathrm{al}^{21}$ found that oxytocin infusion combined with skilful surgical techniques may prevent fluid overload and glycine deficit during TCRE.

Oxytocin stimulated uterine contractions compressed the myometrial vessels and reduced the glycine absorption. The mechanical cervical dilatation and intrauterine manipulation potentiated the effect of the oxytocin. Oxytocin is the agent of choice in the prevention of postpartum uterine atony and bleeding. ${ }^{22,23}$ The dose of oxytocin used in our patients was much lower than those used by Atashkhoei et al, ${ }^{24}$ they used $30 \mathrm{IU}$ in $500 \mathrm{~mL}$ normal saline and they concluded that it was safe and effective in decreasing blood loss during abdominal myomectomy.

Shah et $\mathrm{al}^{25}$ found that spinal anesthesia was a safe and effective method in performing percutaneous nephrolithotomy (PCNL). Hypotension is a common complication of spinal anesthesia. ${ }^{26}$ There was no profound hypotension in our patients and the MAP did not show a statistically significant difference between the control and study group. This was achieved by skilled anesthesiologists with rapid interventions to prevent this complication. We used Propofol in the control group. Use of sevoflurane was associated with significantly more glycine absorption than propofol. $^{27}$

Our results were further enhanced by the use of spinal anesthesia. This was supported by the findings of Moharram et $\mathrm{al}^{28}$ that spinal anesthesia was associated with less glycine absorption. We believed that, because spinal anesthesia did not involve muscle relaxants that were used in the general anesthesia, the abdominal musculature kept the intraabdominal pressure higher than that with general anesthesia. The high intraabdominal pressure reduced the fluid passage through the fallopian tubes into the pelvis which would subsequently be absorbed by the patient. This theory needs to be proved by measuring the intraabdominal pressure in patients under spinal anesthesia and compare it to those under general anesthesia.

Bergeron et $\mathrm{al}^{29}$ found that local anesthesia with sedation was associated with less glycine absorption than the general anesthesia. Unfortunately, there was no setting for local anesthesia with sedation in our hospital. Moreover, the uptake of spinal anesthesia was very low among our population when it comes to non-obstetric surgical operation. The uptake for local anesthesia and sedation was expected to be even lower than the spinal anesthesia.
Florio ${ }^{30}$ concluded that low-dose spinal anesthesia is a feasible technique for operative hysteroscopy in women with high surgical risks.

Goldenberg et $\mathrm{al}^{31}$ found that in patients undergoing endometrial resection, general anesthesia was associated with significantly lower amount of glycine absorption than epidural anesthesia.

We did not use oxytocin infusion in the general anesthesia group since our aim was to examine the impact of combining both spinal anesthesia and oxytocin use on the degree of fluid absorption and not to study the effect of spinal anesthesia alone.

Therefore, to study the effect of spinal anesthetic alone on the fluid absorption and to eliminate the effect of oxytocin, one can compare spinal and general anesthesia with the use of oxytocin in both groups.

In our patients, infertility was an indication for many operations. Roy et $\mathrm{al}^{32}$ concluded that unipolar and bipolar resectoscopes were similar regarding clinical outcomes of infertility and menorrhagia.

We had only one complication (uterine perforation) which was not very likely related to the type of anesthesia or to the oxytocin use.

A key strength of our study was that all patients had an automated glycine infusion. As different glycine infusion rates would be a huge confounder. Moreover, the same surgeon did all the procedures which should remove operator bias.

Our study was limited by the small number of patients and procedures.

Our study is of interest to a wide range of physicians including anesthetists and gynecologists. It will inspire other members of the field as it points to an easy way to reduce a serious complication of a common gynecologic procedure. Our study will drive the academic and clinical discussion to wide application of our intervention to bipolar hysteroscopic operations using electrolyte-containing fluids like normal saline.

\section{Conclusions}

Spinal anesthesia combined with intravenous oxytocin infusion in operative hysteroscopy results in a statistically significant reduction in the glycine fluid deficit than the general anesthesia. The actual clinical implication of our study is to reduce the complications of operative hysteroscopy by reducing glycine absorption. The number of patients in our study was relatively small. We recommend repeating the study on large number of 
patients in a randomized-controlled study. We also recommend studying the effects in operative hysteroscopy using bipolar resectoscope with isotonic solutions.

\section{Abbreviations}

OHIA, operative hysteroscopy intravascular absorption; TURP, transurethral resection of prostate; GA, general anesthesia; U/S, ultra-sound; BMI, body mass index; BP, blood pressure; IU, international unit; ASA, American Society of Anesthesia; L, lumbar; $\mathrm{mmHg}$, millimeter mercury; JUH, Jordan University Hospital; IRB, institutional review board; TCRE, trans-cervical resection of the endometrium; ET, endometrial thickness; MAP, mean arterial blood pressure; EBL, estimated blood loss; GnRH, gonadotrophin releasing hormone; PCNL, performing percutaneous nephrolithotomy.

\section{Author Contributions}

All authors contributed to data analysis, drafting or revising the article, gave final approval of the version to be published, and agree to be accountable for all aspects of the work.

\section{Funding}

The authors received no financial support for the research, authorship, or publication of this article.

\section{Disclosure}

The authors report no conflicts of interest in this work.

\section{References}

1. Laberge P, Leyland N, Murji A, et al. Endometrial ablation in the management of abnormal uterine bleeding. J Obstet Gynaecol Can. 2015;37(4):362-379. doi:10.1016/S1701-2163(15)30288-7

2. Mehta SJ, Roche Recinos A, Saggi SJ, Oh MS. A hypothesis for mechanism for brain oedema due to glycine. Med Hypotheses. 2017;103:58-61. doi:10.1016/j.mehy.2017.03.035

3. Jackson S, Lampe G. Operative hysteroscopy intravascular absorption syndrome. West J Med. 1995;162:53-54.

4. Serocki G, Hanss R, Bauer M, Scholz J, Bein B. The gynecological TURP syndrome. Severe hyponatremia and pulmonary edema during hysteroscopy. Anaesthesist. 2009;58:30-34. doi:10.1007/s00101-0081446-3

5. Hahn R. Fluid absorption in endoscopic surgery. $\mathrm{Br} J$ Anaesth. 2006;96:8-20. doi:10.1093/bja/aei279

6. Sethi N, Chaturvedi R, Kumar K. Operative hysteroscopy intravascular absorption syndrome: a bolt from the blue. Indian J Anaesth. 2012;56:179-182. doi:10.4103/0019-5049.96342

7. de Godoy Borges PC, Dias R, Bonassi Machado R, Borges JB, Spadoto Dias D. Transvaginal ultrasonography and hysteroscopy as predictors of endometrial polyps in postmenopause. Womens Health (Lond). 2015;11(1):29-33. doi:10.2217/WHE.14.50

8. Monteiro CS, Cavallo IK, Dias JA, Pereira FAN, Reis FM. Uterine alterations in women undergoing routine hysteroscopy before in vitro fertilization: high prevalence of unsuspected lesions. JBRA Assist Reprod. 2019;23(4):396-401. doi:10.5935/1518-0557.20190046
9. Di Spiezio Sardo A, Calagna G, Laganà A, et al. Is hysteroscopy better than ultrasonography for uterine cavity evaluation? An evidence-based and patient-oriented approach. $J$ Endometr Pelvic Pain Disord. 2016;8(3):87-93.

10. AAGL Advancing Minimally Invasive Gynecology Worldwide, Munro MG, Storz K, Abbott JA, et al. AAGL Practice Report: practical Guidelines for the Management of hysteroscopic distension media. J Minim Invasive Gynecol. 2013;20:137-148. doi:10.1016/j.jmig.2012.12.002

11. Garry R, Hasham F, Kokri MS, Mooney P. The effect of pressure on fluid absorption during endometrial ablation. J Gynecol Surg. 1992;8:1-10. doi:10.1089/gyn.1992.8.1

12. Paschopoulos M, Polyzos NP, Lavasidis LG, Vrekoussis T, Dalkalitsis N, Paraskevaidis E. Safety issues of hysteroscopic surgery. Ann N YAcad Sci. 2006;1092:229-234. doi:10.1196/ annals. 1365.019

13. Umranikar S, Clark TJ, Saridogan E, et al. BSGE/ESGE guideline on management of fluid distension media in operative hysteroscopy. Gynecol Surg. 2016;13:289. doi:10.1007/s10397-016-0983-z

14. Mavrelos D, Ben-Nagi J, Davies A, Lee C, Salim R, Jurkovic D. The value of pre-operative treatment with GnRH analogues in women with submucous fibroids: a double blind placebo controlled randomized trial. Hum Reprod. 2010;25:2264-2269. doi:10.1093/humrep/ deq 188

15. Muzzi L, Boni T, Bellati F, et al. GnRH analogue treatment before hysteroscopic resection of submucous myomas: a prospective randomized multicenter study. Fertil Steril. 2010;94:1496-1499. doi:10.1016/j.fertnstert.2009.05.070

16. Laganà AS, Palmara V, Granese R, Ciancimino L, Chiofalo B, Triolo O. Desogestrel versus danazol as preoperative treatment for hysteroscopic surgery: a prospective, randomized evaluation. Gynecol Endocrinol. 2014;30(11):794-797. doi:10.3109/ 09513590.2014 .929658

17. Kodama M, Onoue M, Otsuka H, et al. Efficacy of dienogest in thinning the endometrium before hysteroscopic surgery. J Minim Invasive Gynecol. 2013;20(6):790-795. doi:10.1016/j. jmig.2013.04.020

18. Laganà AS, Vitale SG, Muscia V, et al. Endometrial preparation with Dienogest before hysteroscopic surgery: a systematic review. Arch Gynecol Obstet. 2017;295(3):661-667. doi:10.1007/s00404-0164244-1

19. Cicinelli E, Pinto V, Quattromini P, et al. Endometrial preparation with estradiol plus dienogest (Qlaira) for office hysteroscopic polypectomy: randomized pilot study. J Minim Invasive Gynecol. 2012;19 (3):356-359. doi:10.1016/j.jmig.2011.12.020

20. Agostini A, Ronda I, Franchi F, et al. Oxytocin during myomectomy: a randomized study. Eur $J$ Obstet Gynecol Reprod Biol. 2005;118:235-238. doi:10.1016/j.ejogrb.2004.06.032

21. Shokeir T, El-lakkany N, Sadek E, El-shamy M, Abu Hashim H. An RCT: use of oxytocin drip during hysteroscopic endometrial resection and its effect on operative blood loss and glycine deficit. $J$ Minim Invasive Gynecol. 2011;18:489-493. doi:10.1016/j.jmig.2011.03.015

22. Wang CJ, Lee CL, Yuen LT, Kay N, Han CM, Soong YK. Oxytocin infusion in laparoscopic myomectomy may decrease operative blood loss. J Minim Invasive Gynecol. 2007;14:184-188. doi:10.1016/j. jmig.2006.09.016

23. Yamaguchi ET, Cardoso MM, Torres ML, et al. Serum oxytocin concentrations in elective caesarean delivery: a randomized comparison of three infusion regimens. Int $J$ Obstet Anesth. 2011;20:224-228. doi:10.1016/j.joa.2011.03.004

24. Atashkhoei S, Fakhari S, Pourfathi H, Bilehjani E, Garabaghi PM, Asiaei A. Effect of oxytocin infusion on reducing the blood loss during abdominal myomectomy: a double-blind randomised controlled trial. BJOG. 2016;124:292-298. doi:10.1111/14710528.14416 
25. Shah R, Thapa AS, Lamichhane N, Kc SR. Safety and efficacy of spinal anaesthesia in percutaneous nephrolithotomy. J Nepal Med Assoc. 2016;55:61-66. doi:10.31729/jnma.2846

26. Lee JE, George RB, Habib AS. Spinal-induced hypotension: incidence, mechanisms, prophylaxis, and management: summarizing 20 years of research. Best Pract Res Clin Anaesthesiol. 2017;31:57-68. doi:10.1016/j.bpa.2017.01.001

27. Munmany M, Gracia M, Nonell R, et al. The use of inhaled sevoflurane during operative hysteroscopy is associated with increased glycine absorption compared to intravenous propofol for maintenance of anesthesia. J Clin Anesth. 2016;31:202-207. doi:10.1016/j. jclinane.2016.02.012

28. Moharram EE, El Attar AM, Kamel MA. The impact of anesthesia on hemodynamic and volume changes in operative hysteroscopy: a bioimpedance randomized study. J Clin Anesth. 2017;38:59-67. doi:10.1016/j.jclinane.2016.06.023

29. Bergeron ME, Ouellet P, Bujold E, et al. The impact of anesthesia on glycine absorption in operative hysteroscopy: a randomised controlled trial. Anaesth Analg. 2011;113:723-728. doi:10.1213/ ANE.0b013e31822649d4
30. Florio P, Puzzutiello R, Filippeschi M, D’Onofrio P, Mereu L, Morelli R. Low-dose spinal anesthesia with hyperbaric bupivacaine with intrathecal fentanyl for operative hysteroscopy: a case series study. J Minim Invasive Gynecol. 2012;19:107-112. doi:10.1016/j. jmig.2011.08.728

31. Goldenberg M, Cohen SB, Etchin A, Mashiach S, Seidman DS. A randomized prospective comparative study of general versus epidural anesthesia for transcervical hysteroscopic endometria resection. Am J Obstet Gynecol. 2001;184:273-276. doi:10.1067/ mob.2001.108997

32. Roy KK, Metta S, Kansal Y, Kumar S, Singhal S, Vanamail P. A prospective randomized study comparing unipolar versus bipolar hysteroscopic myomectomy in infertile women. J Hum Reprod Sci. 2017;10:185-193. doi:10.4103/jhrs.JHRS_134_16

\section{Publish your work in this journal}

The International Journal of Women's Health is an international, peerreviewed open-access journal publishing original research, reports, editorials, reviews and commentaries on all aspects of women's healthcare including gynecology, obstetrics, and breast cancer. The manuscript management system is completely online and includes a very quick and fair peer-review system, which is all easy to use. Visit http://www.dovepress.com/testimonials.php to read real quotes from published authors. 